\title{
"Viólo por sus ojos, bien sabié la verdat". La vista, la imagen y lo visible en los Milagros de Nuestra Señora
}

\section{"Viólo por sus ojos, bien sabié la verdat". Sight, Image and Visible Things in the Milagros de Nuestra Señora}

\author{
Ana Elvira Vilchis Barrera \\ Universidad Nacional Autónoma de México \\ anaelvira_15@hotmail.com
}

La vista es un sentido privilegiado durante la Edad Media, sin embargo, como el resto del cuerpo, la vista puede ser medio para el error, el engaño y el pecado, de manera que habrá una preocupación constante por las cosas que se miran y su veracidad. Al Más allá cristiano pertenecen los espacios y personajes invisibles cuyo conocimiento directo es inaccesible para la mayoría de los fieles, pero no por ello imposible y menos aún innecesario. Es en la creación artística en donde el Más allá puede hacerse visible: en la representación plástica o en la descripción literaria se pone, literal y metafóricamente, la imagen del Más allá frente a los ojos del público más variado, incluso del menos instruido. En los Milagros de Nuestra Señora, el sentido de la vista es el único de los cinco que se encuentra mencionado en los veinticinco relatos y demuestra la familiaridad de la interacción de los dos planos: terreno y ultraterreno. En este artículo se expondrá la manera en que, a lo largo de la obra, se presenta la polarización semántica que asocia la vista con la devoción, lo verdadero y la salvación, y que opone estos conceptos a los de ceguera, pecado, engaño y condena; para ello se realizará la revisión tanto de las apariciones de personajes divinos o demoniacos, de las almas de los difuntos, como de las representaciones plásticas de Dios y María, que no sólo implican un acercamiento a su imagen, sino también a la mirada constante bajo la cual debe actuar el devoto.

Palabras Clave: vista, milagros, Virgen María, Gonzalo de Berceo, Mester de clerecía

Sight is a privileged sense in the Middle Ages however, as all parts of the body, sight can be a means for error, deceit and sin; this is why there is a constant concern about things that are seen and the veracity of them. Invisible spaces and characters belong to the Christian Beyond, the ones whose direct experience is inaccessible for most devouts, but not always impossible and never unnecessary. In the artistic creation the Beyond can be visible: in plastic representations or literary descriptions the image of the Beyond is, literal and metaphorically, shown to the eyes of a diverse audience, even an illiterate one. In the Milagros de Nuestra Señora, sight is the only out of the five senses mentioned in the 25 stories showing the familiarity of the interaction 
between both planes: earthly and ultra-terrestrial. In the present article, it is shown the way in which, throughout this work of Berceo, the semantic polarization which associates sight with devotion, truth and salvation, and that opposes these concepts to blindness, sin, deceit and damnation; to this purpose it is analyzed both the apparition of divine or demonic characters, deadly souls, and the plastic representation of God and Virgin Mary, which constitute not only the approach to the image, but the constant sight under which the devout should act.

KeYwords: sight, miracles, Virgen Mary, Gonzalo de Berceo, Mester de clerecía

FeCHA DE RECEPCIÓN: 08/02/2017

FeCha DE ACEPTACIÓN: 24/05/2017 
a vista es un sentido privilegiado durante la Edad Media, es el que permite conocer las cosas, incluso a la distancia, e imprimir en la mente y en el alma una imagen del mundo.

San Agustín afirma que la potencia de ver excede a los otros sentidos corporales ya que nos enseña más diferencias de las cosas porque es el más 'espiritualizado y sutil' y está mejor capacitado para aprehender las especies de los objetos. A tal consideración sobre la dignidad espiritual del ojo se añade la potencia física de recibir (antes que los demás sentidos) las sensaciones de los objetos distantes y cercanos y no depender para ello de ningún movimiento, prolongación o sucesión para que la especie se le represente al instante (Delmar, El ojo espiritual, 18-19). ${ }^{1}$

Sin embargo, como el resto del cuerpo, la vista puede ser medio para el error, el engaño y el pecado, ${ }^{2}$ de manera que habrá una preocupación constante por las cosas que se miran y la veracidad de las mismas, ya que no sólo es el mundo real y tangible lo que puede ser visto, sino también los reflejos, las sombras, las reproducciones plásticas, o alguna visión en vigilia o en sueños, en la que puede llegar a verse lo invisible. ${ }^{3} \mathrm{Al}$ Más allá cristiano pertenecen los espacios y personajes invisibles cuyo conocimiento directo es inaccesible para la mayoría de los fieles, pero no por ello imposible y menos aún innecesario. El conocimiento de los espacios y personajes del Más allá resulta indispensable para el cristiano ocupado y preocupado por la salvación de su alma, de manera que ese mundo, invisible a priori, debe ponerse al alcance de aquellas mayorías que no tienen el privilegio de la visión milagrosa. Es en la creación

\footnotetext{
1 "Y se le llama vista porque es vivacior, más importante y más veloz que los restantes sentidos, y tiene una función mucho más amplia $[\ldots]$. Por otra parte, se encuentra muy próxima al cerebro, de donde emana todo" (San Isidoro de Sevilla, Etimologías, XI, I, 849). "Usemos, pues, con preferencia el testimonio de la vista. Es el sentido corporal más noble y el más próximo [...] a la visión de la mente" (San Agustín, Tratado de la Santísima Trinidad, XI, 1, 613).

2 "La imagen del cuerpo visible y la imagen formada en el sentido, denominada visión, apenas son discernibles de no intervenir como juez la razón. Tiene la voluntad tal poder para unir estas dos realidades, que ella aplica al objeto visible el sentido a informar y en él lo retiene una vez informado. Y cuando es tan violenta que pueda llamarse amor, codicia o libido, entonces conturba con gran vehemencia el cuerpo todo del ser animado" (San Agustín, Tratado de la Santísima Trinidad, XI, 2, 5, 621, las cursivas son mías).

3 "Para la filosofía y la estética medievales el mundo visible es el reflejo del mundo invisible. Ver la inmanencia de este en aquél, [... ] descubrir en las formas sensibles la protección de la belleza del alma y de Dios, del orden moral y del orden divino fue la función principal de la imagen para la Iglesia en la Edad Media" (Delmar, El ojo espiritual, 79).
}

Medievalia 49, 2017, pp. 101-120 
artística en donde lo ultraterreno puede hacerse visible: en la representación plástica o en la descripción literaria se pone, literal y metafóricamente, la imagen del Más allá frente a los ojos del público más variado, incluso del menos instruido. Partiendo de lo anterior, se propone aquí un análisis de las menciones del sentido de la vista en los Milagros de Nuestra Señora de Gonzalo de Berceo ${ }^{4}$ y sus funciones como medio para aprehender imágenes y representaciones ${ }^{5}$ de los espacios y personajes ultraterrenos, y permitir así el conocimiento del Más allá.

En los Milagros de Nuestra Señora de Gonzalo de Berceo, el sentido de la vista es el único de los cinco que se encuentra en los 25 relatos $^{6} \mathrm{y}$, al igual que todos, vincula constantemente el plano terrenal con el ultraterreno. Si bien, la vista como sentido corporal refleja la paradójica dualidad del cuerpo, que puede ser medio para la salvación o bien conducto para el pecado, en la obra tiene un sentido mucho más asociado a lo primero que a lo segundo. A lo largo de los 25 relatos de los Milagros se presenta la polarización semántica que asocia la vista con la devoción, lo verdadero y la salvación y opone estos conceptos a los de ceguera, pecado, engaño y condena.

${ }^{4}$ El tema está presente en otras obras, contemporáneas y posteriores no sólo de la tradición hispánica y, además, presenta relación con otras líneas temáticas, la más evidente, la literatura de visiones; sin embargo, la revisión de estas relaciones y contextos rebasa los límites del análisis intratextual que aquí se propone.

${ }^{5} \mathrm{Si}$ bien es cierto que no debe olvidarse la distinción entre el medio de percepción —la vista - y el objeto percibido — imagen o representación—, se hablará aquí de ambos, ya que, por un lado, son nociones intrínsecamente relacionadas, "dichas tres cosas, a saber, la imagen visible del cuerpo, su imagen impresa en el sentido, que es visión y sentido informado, y la voluntad del ánimo aplicando el sentido donde se verifica la visión al objeto sensible, aunque de naturaleza muy diferente, se atemperan en un cierta unidad" (San Agustín, Tratado de la Santísima Trinidad, XI, 2, 5, 621), por otro lado, el objetivo que aquí se plantea es, precisamente, relacionar el sentido con la imagen visible — dejando de lado la noción agustiniana de la voluntad - y analizar las funciones narrativas del sentido de la vista cuando permite percibir un ámbito distinto al material a través de la imagen y la representación.

${ }^{6}$ Se enlistan a continuación las cuadernas donde el sentido de la vista se menciona de manera relevante para el presente estudio: I.59, 64, II.86, III.105, 111, IV.116, 123-124, 131, v.139, VI.145, vir.169, viII.188-192, 198, 204, IX.223, 228, x.242-243, 247-248, 264, XI.279, XII.305, XIII.308, XV.399, xVI.357-358, xVII.394, 402-404, 407-409, xVIII.427, xIx.441442, 448, 456, xx.466-490, xxı.518, 528-535, xxıI.586-587, 597-600, xxıII.649, 675-677, XXIV.720, 734, 777, 781, 811, 822, 850, xxv.879. El milagro XIV no se encuentra en la enumeración anteriror debido a que se distingue del resto por la ausencia de un beneficiario humano, sin embargo, al tratarse de una imagen, de una representación visual de la Virgen, la vista es, en realidad, el único sentido presente en esta narración. (La numeración de los milagros y las cuadernas, así como las citas de la obra que se presentarán en las siguientes páginas, siguen la edición de Fernando Baños, señalada en la bibliografía; en las citas que se presentarán más adelante, las cursivas son mías).

Medievalia 49, 2017, pp. 101-120 
Frente a los once milagros ${ }^{7}$ en los cuales la Virgen es vista por algún devoto o pecador arrepentido, el Diablo se aparece sólo en tres milagros. ${ }^{8} \mathrm{Si}$ existe en la tradición judeocristiana un personaje representativo del engaño es el Diablo, no sólo por sus palabras y obras, sino por su apariencia: si Dios es el señor de toda la creación, el Diablo, al oponerse a Él, queda relegado a una falta de forma propia, con lo cual adopta múltiples aspectos sin que ninguno le pertenezca realmente. En los Milagros, Dios no se ve si no es en la imagen de Cristo. Por el contrario, el Diablo sí se presenta de manera visible, ya sea de forma monstruosa y por tanto aterrorizante — generalmente parcial o totalmente zoomorfo- $\mathrm{o}$, paradójicamente y en oposición a lo monstruoso, transfigurado en alguien conocido o bello, ya que "con sus armas favoritas, la tentación y el engaño, busca introducir en el corazón de los hombres deseos ilícitos y suscita malos pensamientos [...]. Para estos fines puede usurpar una apariencia humana, particularmente la de una mujer seductora o la de un joven hermoso, inclusive la de un santo" (Baschet, La civilización feudal, 412). En el milagro viII, el Diablo que se transfigura para ganar la confianza del romero:

\section{Transformóse el falso en ángel verdadero, paróseli delante en medio un sendero: "Bien seas tú venido — díssoli al romero- seméjasme cossiella simple como cordero".}

$\left(\right.$ VIII.188) ${ }^{9}$

Esta irrupción demoniaca "se explica fácilmente, en el siglo XIII, al sostenerse que el mundo de los hombres no está cerrado sino que comunica con el de los diablos" (Ruiz, El mundo espiritual, 121) y, de manera más alentadora, comunica también con el plano celestial, gracias a lo cual el romero es salvado. El engaño mediante la falsa apariencia se convierte en el eje del relato y en el principal argumento que el apóstol Santiago expone a la Virgen para salvar

\footnotetext{
${ }^{7}$ Milagros I, III, IV, IX, XIII, XV, XVI, XIX, XX, XXI y XXIV.

${ }^{8}$ Milagros viII, xx y xxIv. Cabe recordar aquí el significado de 'aparecer': "manifestarse, dejarse ver, por lo común, causando sorpresa, admiración y otro movimiento del ánimo” (DLE, s.v. aparecer), ya que, precisamente, todas de las apariciones que tienen lugar en las obras que aquí se estudian, sean divinas o diabólicas, tendrán un fuerte efecto, no sólo en el ánimo, sino en las acciones de quien las experimenta.

${ }^{9}$ Los Milagros de Nuestra Señora se cita siguiendo la edición de Fernando Baños (Madrid: Real Academia Española, 2011), se señala entre paréntesis el número de milagro y las cuadernas; en todos los casos, las cursivas son mías.
}

Medievalia 49, 2017, pp. 101-120 
a su devoto, haciendo explícita la ofensa que el Diablo ha cometido al usurpar su imagen para cometer el engaño y condenar un alma.

Prisi muy grand superbia de la vuestra partida:

tengo que la mi forma es de vós escarnida,

matastes mi romeo con mentira sabida,

demás veo agora la alma maltraída

(vIII.204)

El engaño visual funciona además como advertencia y recordatorio de los temores constantes: la aparición milagrosa puede ser una trampa para el pecador, el Diablo es traidor y puede tomar cualquier forma, ante el rome106 ro "mostrávase por bueno, en berdat no lo era" (viII.186d); por lo tanto, se aconseja a los devotos que sean cautos, incluso ante la imagen de aquellos que parecen confiables.

El dïablo antigo siempre fo traïdor, es de toda nemiga maestro sabidor, semeja a las vezes ángel del Criador, e es dïablo fino, de mal sosacador.

(vIII.187)

Llama la atención el hecho de que, aunque en este caso la aparición misma no es monstruosa, sí conduce a una muerte sumamente violenta tanto para el cuerpo — mutilado - como para el alma — condenada por el suicidio-, lo cual, para un público cristiano constantemente preocupado por la salvación, resultaría aterrador.
Si tú no li dissiesses que Santïago eras,
tú no li demostrasses señal de mis veneras,
non dañarié su cuerpo con sus mismes tiseras
nin yazdrié como yaze fuera por las carreras.

(vIII.203)

En el milagro xx, el Diablo se aparecerá en forma de toro, can y león al monje beodo. El relato es ubicado temporalmente "[... ] a ora de vísperas, el sol bien enflaquido" (xx.464a), y el ambiente nocturno y, por ende, oscuro en donde se aparecerá en tres ocasiones el Diablo contrasta conla imagen del "otro día mañana, venida la luz clara” (xx.491a) en la que encontramos al monje salvado, arrepentido 
y penitente; el contraste 'oscuridad / luz' puede equipararse con 'condena / salvación' si recordamos que la luz es una analogía de la gracia divina según los filósofos neoplatónicos (cf. Delmar, El ojo espiritual, 17). ${ }^{10}$ En este caso, la aparición diabólica en forma de bestias fieras es agresiva, aunque presenta cierta familiaridad, ya que el temor a la ferocidad de un animal es algo conocido e identificable, es una aparición que "atemoriza pero no sorprende" (Ruiz, El mundo espiritual, 121):

En figura de toro que es escalentado, cavando con los piedes, el cejo demudando, con fiera cornadura, sañoso e irado,

$[\ldots]$

Facieli gestos malos la cosa dïablada, que li metrié los cuernos por media la corada;

$[\ldots]$

en manera de can firiendo colmelladas.

Vinié de mala guisa, los dientes regañados, el cejo mü̈ turbio, los ojos remellados, por ferlo todo pieças, espaldas e costados, [... en forma de león, una bestia dubdada, que trayé tal fereza que non serié asmada.

Allí cuidó el monge que era devorado, ca vidié por verdat un fiero encontrado, peor li era esto que todo lo passado

Ahora bien, las apariciones del Diablo como bestia, dan pie a que la Virgen se presente para defender aguerridamente a su devoto. Las descripciones de la imagen mariana son realmente escasas, ${ }^{11}$ lo que se muestra con detalle es la manera en que la Virgen derrota al Diablo en las tres ocasiones ante la

${ }^{10}$ En la obra, la analogía luz/salvación también presente de forma explícita en voz de María, quien llama a Cristo crucificado "luz de los pecadores" (xvin.419).

${ }^{11}$ De las escasas descripciones de la Virgen se hablará más adelante. En este milagro sólo la encontramos descrita en algunos versos de estas tres cuadernas: "Vino Sancta María con ábito onrado, / tal que de omne vivo non serié apreciado" (xx.468ab), "mas valio.l la Gloriosa, es cuerpo adonado” (xx.472c), "La Reïna preciosa e de precioso fecho” (xx.482a).

Medievalia 49, 2017, pp. 101-120 
mirada del aterrorizado monje, la descripción es casi teatral, no sólo el monje sino el público puede visualizarla sin dificultad: ${ }^{12}$

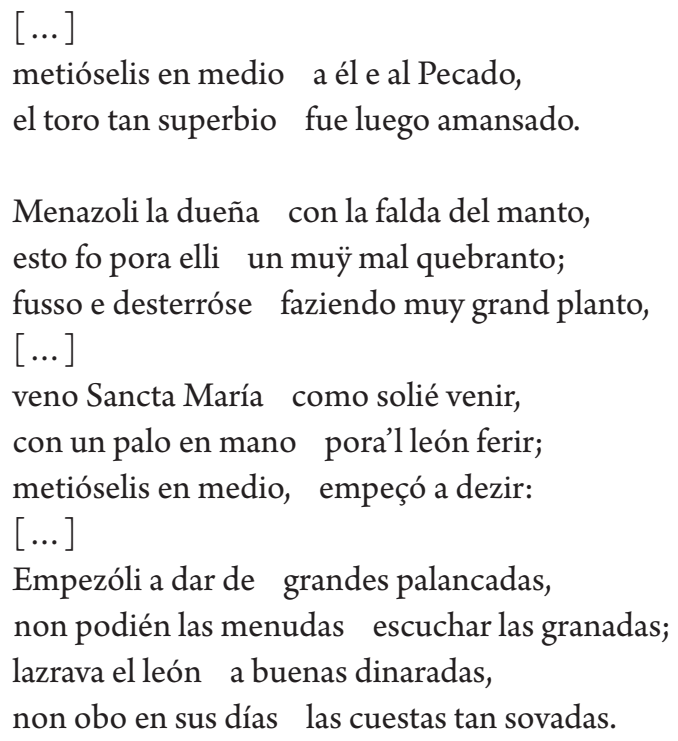

$(\mathrm{xx} .468-478)$

La última aparición del Diablo en los Milagros de Nuestra Señora es la del relato de Teófilo, donde se conjugan la oscuridad de la noche que encontrábamos en el milagro xx y el encuentro a mitad del camino del milagro viII, ambos elementos otorgan el contexto propicio para lo oculto y lo engañoso de la corte demoniaca. Aquí, la descripción del Diablo y su corte es terrorífica y violenta por las consecuencias del encuentro y no por su aspecto, que es descrito con brevedad:

Prísolo por la mano, la nochi bien mediada, sacólo de la villa a una cruzejada;

[...]

Vio a poca de ora venir muy grandes gentes con ciriales en manos e con cirios ardientes, con su reÿ en medio, feos, ca non luzientes; ¡ya querrié don Teófilo seer con sus parientes!

(xxIv.733-734)

\footnotetext{
${ }^{12}$ El triunfo final de la Virgen en el relato se refiere también en términos visuales: "Desfizo la figura [del Diablo], empezó a foír" (xx.480).
} 
En este caso podría observarse una mayor complejidad doctrinal en el milagro: la aparición del Diablo resulta atemorizante ya que no se trata de un pecador incauto engañado, ni de la visión de las bestias feroces, sino que se trata de un devoto - antes lleno de virtudes - que se ha visto cegado por el pecado: "[...] aviélo la envidia de su siesto sacado [...] cegó con grand despecho e fo mal trastornado, / asmó fiera locura, yerro grand, desguisado" (xxIv.719-720), y es a causa de esta ceguera que se condena su alma. ${ }^{13}$ Para el público, una experiencia mucho más violenta y tangible que el encuentro demoniaco, es la dolorosa enfermedad a la que Teófilo se ve sometido, sin embargo, los dolores son enviados por Dios con el fin de salvar su alma, ya que "El Señor, que non quiere muerte de pecadores, / mas que salven las almas, emienden los errores, / [por lo cual] tornó en est enfermo de mortales dolores" (xxIV.748abc). Así, Dios impone la penitencia para Teófilo: el sufrimiento corporal como medio - excesivo, ya que el pecado ha sido terrible — para la salvación; y es gracias a la enfermedad que el pecador abre los ojos:

Los vienes que fiziera ennos tiempos trocidos el buen Señor non quiso que li fuessen perdidos; reviscló los sus sesos, que yazién amortidos, abrió luego los ojos que tenié adormidos. ${ }^{14}$

(xxIv.749)

De igual manera, los caballeros de la Iglesia profanada “[... en fer el pecado fueron ciegos e botos" (XVII.404a) y los ladrones que roban el templo son milagrosamente castigados con la pérdida de la vista: "Andavan tanteando de rencón en rencón / como fazié Sisiñio el celoso varón" (xxv.886). ${ }^{15} \mathrm{De}$ lo anterior se sigue que el pecado será constantemente vinculado a la carencia de la vista. Además, el pecado — como conducta humana que afecta tanto al cuerpo como en el alma, que repercute tanto en los gozos y sufrimientos

\footnotetext{
${ }^{13}$ Llama la atención en el relato la marca de que Teófilo pierde su sombra al hacer el pacto con el Diablo, en algunas tradiciones, la sombra se vincula con "la parte de un ser humano capaz de escindirse del cuerpo, particularmente en el momento de la muerte" (Harpus, La tradición, 20), en este caso, al momento de la condena.

${ }^{14}$ Hay que enfatizar también la aparición del sentido de la vista en las siguientes tres cuadernas: Teófilo se ve como pecador, cree que nunca verá recobrada la salvación de su alma, y se compara con un náufrago que no ve tierra firme (cf. xxiv.750-752).

${ }^{15}$ Cabe resaltar aquí la semejanza entre el milagro de Sisiñio y el relato de Berceo, ya que en ambos la pérdida repentina de la vista es el medio para que la Iglesia - como templo y como congregación - sea resguardada de los pecadores.
}

Medievalia 49, 2017, pp. 101-120 
terrenales como en los de la vida eterna- puede verse, siempre y cuando el sujeto no se encuentre inmerso en él; idea que está presente no sólo en la literatura, sino en el pensamiento científico-moral de la época:

el ojo colocado en un medio caliginoso no ve ni comprende los vapores y nubes que lo circundan, pero apartándose de este aire nebuloso, si mira directamente, ve aquel aire caliginoso que antes no veía estando colocado en él. Del mismo modo el pecador, en tanto que está en el pecado, no ve las tinieblas del mismo. Pero después de que se pone fuera del pecado y es iluminado por la luz de la gracia divina, reconoce la gravedad del pecado y la oscuridad de él en la que estaba situado (Limoges, Libro devoto, 63).

110 A partir de la posibilidad de plantear al pecado como un elemento visible para los hombres, para Dios y la corte celestial y al pecador como aquel que no ve, puede afirmarse que el hombre devoto y virtuoso será el que sea capaz de ver su pecado, y el que sea consciente de que Dios y la Gloriosa pueden verlo también. En los Milagros, esto se encuentra, primero, en la petición de que no se miren los pecados, los errores o la falta de méritos del suplicante: "Madre — disso Teófilo- , por Dios e caridat, / non cates al mi mérito, cata a tu bondat" (xxiv.781ab); en segundo lugar, en la certeza de que Dios puede verlo todo, sin que exista posibilidad de ocultarle cosa alguna: "fuera Dios, a cual sólo non se encubre nada" (xxIv.742cd), "Dios el Nuestro Señor, alcalde derechero, / al que non se encubre bodega nin cellero" (x.244ab); y en tercer lugar, se encuentra la posibilidad de ver algún pecado concreto - como uso metafórico de la actitud que se observa en el pecador-: "ca veo que traedes muy grand alevosía" (viri.205d) le dice Santiago al Diablo. Sin embargo, que María no mire a Teófilo arrepentido, que aparte de él su rostro - y por extensión no escuche sus plegarias - parece ser el peor de los castigos, del cual se sabe merecedor y por lo cual implora perdón:

Torna contra mí, Madre, la tu cara preciosa, fáceslo con derecho si me eres sañosa; non vaya más a mal que es ida la cosa, torna sobre Teófilo, Reïna glorïosa.

$($ XxIv.775)

De manera que, si bien la mirada divina es infalible, inevitable y juiciosa, verse privado de ella se plantea como una terrible ruptura del vínculo comunicativo que conduciría al aislamiento del pecador y por lo tanto anularía su posibilidad de redención y salvación. 
Ahora bien, como ya se mencionó, en los Milagros, son once los relatos en los que la Virgen se aparece a sus devotos en vida. La primera aparición es, en sí misma, "un present muy onrado" (I.58d) que hace la Virgen al devoto San Ildefonso, y la descripción de la Gloriosa con el libro del santo en la mano implica, sin duda, el completo favor con el que ella premia a su vasallo y, por extensión, el favor que puede alcanzar Berceo como devoto que también está escribiendo una obra sobre los milagros marianos:

$$
\begin{aligned}
& \text { Aparecio.l la madre del Rey de Magestat } \\
& \text { con un libro en mano de muy grant claridat, } \\
& \text { el que él avié fecho de la virginidat; } \\
& \text { plógo.l a Illefonso de toda voluntat. }
\end{aligned}
$$

Sin embargo, no todas las apariciones marianas en los Milagros se dan en un contexto armonioso. Además de la aparición ante San Ildefonso, la Virgen se aparece en otras tres ocasiones para mostrar el favor que tiene hacia algún devoto y brindar auxilio o consuelo: al clérigo moribundo en el milagro IV, a la parturienta en el XIX y al monje embriagado en el xx, antes mencionado. En estos tres casos, al igual que ante la abadesa encinta (xxi) y Teófilo (xxIv) la Virgen se aparece en un momento de crisis para el beneficiario - agonía o peligro-; los dos últimos se distinguen porque la aparición será la respuesta - primero visual, luego verbal — a las oraciones de los dos religiosos arrepentidos. Por su parte, en los milagros XV y XVI, las apariciones ${ }^{16}$ ante el novio y el niño judío, respectivamente, se mencionan de manera casi implícita, sin embargo, en ambos casos la visión provoca un cambio trascendental en los personajes beneficiarios: la reafirmación de la fe del novio y la conversión del judezno, ${ }^{17}$ en ambos se gana un devoto leal más para el culto mariano.

En tres milagros más, las apariciones de María no tienen el contexto ni el carácter amable que se esperaría de la principal figura maternal e intercesora

\footnotetext{
${ }^{16}$ Hay que tener presente que, en el milagro del niño judío (XVI), la descripción de la Virgen es estática y por lo tanto bastante cercana a una imagen plástica, esto se acentúa ya que se trata del único milagro en que la Virgen se aparece pero no habla. Por otro lado, en el milagro xv, la visión del novio, que tiene lugar antes de que la Virgen empiece a reclamarlo como esposo: "vínoli la Gloriosa, plena de bendición, / com qui sañosamientre díssoli tal razón” (xv.339cd) se hace explícita seis cuadernas después "mas aviélo turrado mucho la vissïón" (xv.345d).

${ }^{17}$ Cabe recordar aquí la creencia de que "los rayos emanan de la cosa vista y transportan al ojo las cualidades del cuerpo observado. De ahí que, como le sucede al clérigo de la historia de Berceo, lo que vemos nos transforma” (Delmar, El ojo espiritual, 23).
}

Medievalia 49, 2017, pp. 101-120 
del cristianismo: en los milagros III, IX y XIII la Virgen se aparece a personajes secundarios para dar instrucciones que favorezcan a sus devotos; ${ }^{18}$ en el milagro IX el obispo se muestra espantado tras las amenazantes palabras de María, sin embargo, la aparición se menciona pero no se describe. En los milagros III y XIII la visión resulta insuficiente para que los devotos estén seguros de que se trata de la Virgen, ya que tanto el clérigo como el "omne católico", ante los cuales se aparece, cuestionan la identidad y el mensaje de María, por lo que resulta necesario que ella comunique claramente ambas cuestiones mediante la palabra, la imagen se convierte así en un apoyo recurrente para la palabra en los Milagros.

En todos los casos, la aparición de María es, en sí misma, milagro y testimonio en la tierra. Como milagro, se explica la reacción de miedo o de duda 112 al contemplar lo maravilloso cristiano; como testimonio, la visión funciona como un apoyo para reforzar la devoción en la comunidad, sin embargo, al ser las visiones una manifestación de la divinidad dirigida a un receptor individual ${ }^{19}$ es necesaria la transmisión oral del milagro para que llegue a la colectividad.

El único relato en que la Virgen es observada en el Más allá es el milagro vII, en el que Cristo ve a su madre y al séquito de vírgenes que la acompañan cuando va a interceder por el alma del monje de San Pedro. En este caso, como en las ocasiones en que María es vista en la tierra, la imagen es preámbulo para el diálogo. Hay que notar que el alma del monje también puede ver la procesión mariana, ya que, como se menciona más adelante, las almas en el Más allá también pueden ver y ser vistas.

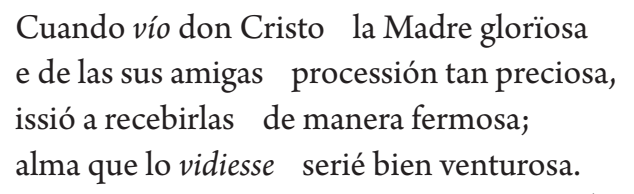

(vII.169)

\footnotetext{
${ }^{18}$ En algunos casos sus palabras son bastante agresivas, basta recordar el relato del clérigo simple, en el cual "La Virgo glorïosa, madre sin dición, / apareció.l al bispo luego en visïón; / díxoli fuertes dichos, un brabiello sermón, / descubrióli en ello todo su corazón” (Ix.228).

${ }^{19}$ Sólo en el milagro IV se presenta la posibilidad de que los testigos, y no sólo el beneficiario, hayan presenciado la visión milagrosa, sin embargo, el verso "Cuantos la voz udieron e vidieron la cosa” (IV.131a) aparece al final del relato, por lo que resulta ambiguo al señalar si los testigos tuvieron conocimiento sensible de la visión o sólo del relato del milagro.
} 
Por lo demás, las apariciones marianas tienen lugar, como ya se ha comentado, en la tierra y en vida de los devotos pero, a pesar de su indudable protagonismo en la obra, las descripciones de la Virgen en los 25 milagros, son realmente escasas. Además de las presentes en los milagros I y Xx, anteriormente citadas —en donde más que describir la figura o facciones marianas, se mencionan los elementos que porta en las manos, su actitud o algún detalle de su vestimenta-, se encuentra otra breve mención a sus ropas como instrumento de protección —-muy extendida en las artes plásticas — en el milagro del parto maravilloso: "Yo en esto estando, vino Sancta María, / cubrióme con la manga de la su almexía" (xIX.448ab); también encontramos, en el milagro de la abadesa encinta, la mención a los seres que la acompañan durante la aparición: "dos ángeles con ella de muy grand claridad" (xxi.529d), mismos que no pueden considerarse tan sólo como un complemento visual ya que tendrán la función narrativa de poner a salvo al hijo de la abadesa; por último, tal vez la imagen que se describe con más detalle sea la que mira el niño judío, en donde el rasgo que destaca es la belleza de María:

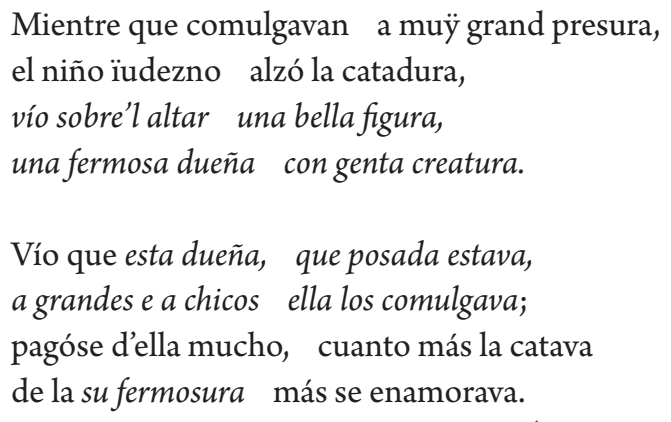

(vIII.357-358)

Como puede observarse, la aparición mariana no se enmarca en un contexto particular - puede ocurrir en espacios religiosos o no específicos, de día o de noche, después de la oración o de manera espontánea, a clérigos o a laicos-, con lo cual Berceo presenta una posibilidad de encuentro visual bastante amplia con María, sin proponer jamás una imagen particular de la Virgen y menos aún de alguna advocación. La visión suele vincularse con los sentidos del oído y el tacto, a los que sirve de apoyo. En el milagro de Teófilo encontramos, por ejemplo, que son tres las veces que María se aparece al pecador, la última, a diferencia de las dos anteriores, ocurre sin diálogo alguno: "vínoli la Gloriosa con recabdo complido, / con su carta en mano, queda e sin roído" (xxIv.822cd), es decir, la Virgen se aparece tan sólo para entregar 
la carta que ha recuperado del Infierno — prueba tangible de la redención de Teófilo-.

Por otro lado, en los Milagros se mencionan, aunque tampoco se describen, algunas imágenes pictóricas o escultóricas de la Virgen. Precedidas por una complicada historia de argumentos a favor y en contra de la representación plástica de Dios, de la Virgen y del resto de la corte celestial, el cristianismo del siglo XIII, al cual pertenece la obra de Berceo, parece tener ya bien asimilada la idea de que la imagen cumple la función de concentrar y dirigir la atención del devoto que hace oración e inspirar su fe; las imágenes como "prototipos corpóreos de los seres divinos, inmateriales y espirituales" deben ser un apoyo "para que nuestra humana condición fuera capaz de su contemplación y veneración” (Carmona, Iconografía cristiana, 21). Resulta siempre más comprensible para el devoto tener una imagen a quien dirigirse en las súplicas, que hacerlo ante la idea abstracta de la divinidad. Como ejemplo de ello, se encuentra a la abadesa encinta que ruega ante la imagen mariana:

$$
\begin{aligned}
& \text { Devatióse en tierra delante el altar, } \\
& \text { cató a la imagen, empeçó de llorar, } \\
& \text { "Valme - dixo-, Gloriosa, estrella de la mar, } \\
& \text { ca non é nul consejo que me pueda prestar". }
\end{aligned}
$$

$($ XxI.518)

Por otro lado, las imágenes plásticas cumplen una importante función didáctica entre los fieles, más aún al pensar en una comunidad mayoritariamente analfabeta "la imagen no sólo enseña e informa, sino que puede, mejor que la palabra escrita, conmover a los fieles y orientar su comportamiento hacia los valores cristianos" (Carmona, Iconografía cristiana, 19). Podemos recordar, por ejemplo, el milagro del mercader fiado donde la imagen divina funciona como aval del mercader y testigo del pago al judío, está ahí la marca inicial de que el devoto "mostróli" (XXIII.649b) al prestamista judío la imagen de su Señor y su Dama, que será la misma que luego — mediante el milagroso testimonio oral - logre la conversión del judío y sus compañeros, es decir, la orientación hacia los valores cristianos.

La imagen resulta ser, además, un recordatorio material de la omnipresencia de Dios y de María, que apoya la concepción de una mirada divina a la cual nada se le oculta. Muestra de ello es el clérigo del milagro IV que se avergüenza ante la mirada de la imagen plástica de María, que funciona como extensión a la mirada sentenciosa y omnipresente de la divinidad — de la que ya antes se habló-: 


\begin{abstract}
De un clérigo otro nos diz la escriptura que de Sancta María amava su figura, siempre se inclinava contra la su pintura, avié muy grand vergüenza de la su catadura.
\end{abstract}

Si bien no debe olvidarse que "la verdadera adoración estaba reservada a Dios, y $[\ldots]$ quien venera a una imagen venera a la persona que ella representa" (Carmona, Iconografía cristiana, 21), encontramos en los Milagros de Nuestra Señora un fuerte reflejo de la religiosidad popular, ya que, aunque dogmáticamente la imagen no puede ser en sí misma objeto de adoración, porque tal cosa sería caer en idolatría, para la devoción del pueblo las imágenes plásticas tienen un sentido mucho más vital y animado que el de la mera representación, así que en la obra, ya sea por acción milagrosa o por fe, adquieren la capacidad de ver y hablar, ejemplos de ello se encuentran en la mirada de la pintura del milagro IV y en la voz del crucifijo del xxiII —ya mencionados- y, claro, en las prodigiosas reacciones de las imágenes vulneradas, por el incendio y los ladrones, en los milagros XIV y XXV, respectivamente. Así, las representaciones plásticas de Dios y María no sólo implican un acercamiento a su imagen, sino también a la mirada constante bajo la cual debe actuar el devoto.

Si bien Berceo no describe puntualmente la imagen de María en las visiones, sí la menciona como Señora y con el niño Jesús en brazos: la maternidad y la majestad de la Virgen son los dos aspectos que visualmente destacan en la obra. Incluso en el milagro de la imagen respetada por el incendio, donde la imagen escultórica funciona como protagonista del relato, encontramos la descripción — breve — que resalta estos dos aspectos, sobre todo mediante la mención a los ornamentos que rodean la imagen, pero tampoco aquí se presenta una descripción física de la Virgen:

$$
\begin{aligned}
& \text { [...] } \\
& \text { en él rica imagen de precio muy granado. } \\
& \text { Estava la imagen en su trono posada, } \\
& \text { so Fijo en sus brazos -cosa es costumnada-, } \\
& \text { los reyss redor ella, sedié bien compañada, } \\
& \text { como rica Reina de Dios santificada. } \\
& \text { Tenié rica corona, como rica Reïna, } \\
& \text { de suso rica impla en logar de cortina; }
\end{aligned}
$$


era bien entallada de lavor muÿ fina;

valié más essi pueblo que la avié vezina.

Colgava delant ella un buen aventadero, en el seglar lenguage dízenli moscadero; de alas de pavones lo fizo el obrero: luzié como estrellas, semejant de luzero.

(xIv.318-321)

La imagen mariana permanece, durante toda la obra, como un punto de indeterminación para los receptores. ${ }^{20}$ Que no exista una descripción precisa de la imagen de María puede explicarse por la voluntad de ajustarse a cualquiera de las imágenes de las diversas advocaciones que conociera el receptor o argumentando que una descripción precisa resulta innecesaria al ser la Virgen tan familiar y conocida, una realidad presente menos por su imagen que por los milagros que logra en favor de sus devotos. ${ }^{21}$

Por otra parte, si bien el hecho de ver a un personaje del Más allá en la tierra es, en sí mismo, un suceso milagroso, cuando los relatos se sitúan en el espacio ultraterreno, la presencia de estos personajes es esperada, aunque la visibilidad de los personajes divinos en los Milagros no es una constante: sólo en el milagro vir hay mención explícita de la Gloriosa y el coro de vírgenes observadas por Cristo, como se mencionó anteriormente. Lo que resalta en el Más allá es la visibilidad de las almas humanas — que adquieren además características materiales-. Al igual que en las representaciones pictóricas contemporáneas, las almas se presentan en la obra de dos maneras: como figuras humanas o como aves. ${ }^{22}$

${ }^{20}$ Citando a Ingarden, “con base en el texto, no se puede saber con exactitud cómo está determinado el objeto correspondiente” (“Concretización”, 33), en este caso, cómo se determina la imagen de la Virgen. Para Delmar "si nos apoyamos en una diferencia teológica básica, advertimos que las imágenes de Berceo, como autor, eran exteriores y las del lector, como las del clérigo [del milagro IV] que contemplaba la pintura de la Virgen, interiores" (El ojo espiritual, 14), marcando así la distinción entre la imagen exterior que otorga tan sólo algunos rasgos de los cuales partir para que los lectores completen la indeterminación.

${ }^{21}$ La ausencia de una descripción precisa de la Virgen en estas obras puede entenderse, guardando las diferencias temporales e ideológicas, por analogía con la ausencia de representaciones de Dios en el Antiguo Testamento, "si bien el pueblo no tiene forma o manera de representar a su Dios Yahwé [... Él se hace en realidad presente para el pueblo en las acciones que realiza a lo largo de la historia de ese pueblo" (Soto-Hay, Signos y símbolos, 310).

${ }^{22}$ En el milagro del romero naufragado, de manera simbólica, las almas de los náufragos se transfiguran en palomas, que son vistas en el plano terrenal por el romero y los testigos

Medievalia 49, 2017, pp. 101-120 
El mundo medieval tan preocupado por el 'más allá debía tener una clara representación del alma [...]. Con la representación del alma por medio de la figura humana no hay una sustitución provocada por la inaccesibilidad de lo invisible, sino más bien una continuidad de lo visible (Herrero, "Notas iconográficas", 26).

Así, en los Milagros, las almas de los difuntos pueden ser objeto de diversas miradas en el Más allá: pueden ser vistas, en primer lugar, por los demonios que propinen las diversas torturas - descritas en términos corporaleso por los ángeles que intenten brindar su auxilio, casos en los que queda muy clara la representación visual de las almas como una continuación del cuerpo material:

Mientre que los dïablos la trayén com a pella, vidiéronla los ángeles, descendieron a ella; ficieron los dïablos luego muy grand querella: que suya era quita, que se partiessen d'ella.

Vidiéronla los ángeles seer desemparada, de piedes e de manos con sogas bien atada; sedié como oveja que yaze ensarzada; fueron e adussiéronla pora la su majada.

En segundo lugar, las almas en el Más allá también pueden ser objeto de la mirada de los santos, ya sea de manera juiciosa o como preámbulo para justificar la intercesión:

Ellos que la levavan non de buena manera, víolo Sanctiago, cuyo romeo era

(viII.198ab)

Violo Sant Laurencio, católo feamientre, $[\ldots]$

cuando suben al cielo (xxiI.599-600), la representación del alma en forma de ave se usa generalmente para aludir a las almas de los santos o los mártires, en el caso del milagro puede ser testimonio visual de la salvación de los náufragos (cf. Herrero, "Notas iconográficas", 23-25).

Medievalia 49, 2017, pp. 101-120 
Violo Sancta Agnés a qui tollió el huerto, tornóli las espaldas, cató.l con rostro tuerto.

(x.242-243)

Finalmente, las almas pueden ser objeto de la mirada de otra alma; como recurso literario para hacer visible la condena, las ánimas son vistas cuando los diablos las llevan y las maltratan, o bien, ya en el Purgatorio, recibiendo los castigos merecidos por los pecados:
Aviénla ya levada cerca de la posada
do nunca verié cosa de que fuesse pagada:
nin verié sol ni luna, nin buena rucïada,
e serié en tiniebra como emparedada.

Vío a su hermano con otros pecadores

do sedié el mesquino en muy malos sudores;

metié vozes e gritos, lágrimas e plangores,

avié grand abundancia de malos servidores.

(x.247-248)

En el milagro $x$, como puede verse, los castigos ultraterrenos implican la carencia de luz y, por lo tanto, la imposibilidad de que el alma vea, con lo que la ceguera que en un principio quedaba asociada con el pecado en la tierra, se asocia en el Más allá con la condena del alma que, en los Milagros, puede ser observada como una advertencia - para personajes, lectores u oyentes- . Por el contrario, la salvación, aunque aparece en voz de los beneficiaros, no se describe en términos visuales sino más bien relacionados con el tacto y el gusto. ${ }^{23}$

Finalmente, la vista funciona también en el plano terreno para evidenciar la veracidad de los milagros. Hay casos en que los testigos ven alguna señal que es consecuencia del milagro — la flor en la boca del clérigo (III.112-113), las cicatrices del romero de Santiago resucitado (virI.211-213) o de los ladrones que profanan la iglesia (xvir.407-409), la ausencia de señales de embarazo de la abadesa (xxi.560), o el resplandor que rodea a Teófilo redimido (xxiv.850-854)—. En otros casos, la acción milagrosa puede observarse: en el relato del mercader fiado, parte del suceso milagroso se presenta como algo visible - la imposibilidad maravillosa de que la deuda sea cobrada por quien no sea el acreedor-:

${ }^{23}$ Sirvan como ejemplo las siguientes cuadernas, respecto al gusto: XII.298; respecto al tacto: IV.129, v.137-138, VII.174 y XII.297. 
“esto vidiénlo muchos, judíos e cristianos" (xxıII.675d). Por su parte, el milagro del parto maravilloso ocurre, según el narrador, porque Dios quiere hacer visible el poder de su Madre en la tierra: "quísolis grand miráculo Don Cristo demostrar, / por ond de la su Madre oviessen qué fablar" (xIX.441cd). En palabras del mismo Berceo, el sentido de la vista funciona, en el plano terreno, no sólo como medio para captar la verdad, y por lo tanto como prueba al dar testimonio de los sucesos milagrosos: "víolo por sus ojos, bien sabié la verdat" (XXII.586d); sino que también funciona para dar actualidad a los milagros: "Los antigos miráculos, preciosos e onrados, / por ojo los veemos agora renovados" (XIX.456a).

La vista, en los Milagros de Nuestra Señora, demuestra la familiaridad dela interacción de los planos terreno y ultraterreno, interacción que puede manifestarse en términos plásticos. La vista es un sentido de presencias y ausencias enla obra, se ve la oscuridad del purgatorio pero no la salvación, las representaciones plásticas pueden ser vistas por la comunidad, pero la visión divina está reservada a algunos dichosos devotos, María se aparece, pero nunca es puntualmente descrita; en última instancia la polaridad semántica que vincula los conceptos de pecado y ceguera opuestos a los de salvación y vista mantiene total coherencia si pensamos en los lectores u oyentes como romeros en el camino de la salvación que, si bien pueden tener un atisbo del Más allá, deben mantener la devoción constante, siempre atentos a lo que miran, para obtener, al final del peregrinaje, la visión de la Gloria.

\section{BIBLIOGRAFÍA CITADA}

Agustín, San, Tratado de la Santísima Trinidad, trad. de L. Arias, t. V, Madrid: Biblioteca de Autores Cristianos, 1956.

BASCHET, JÉRÔME, La civilización feudal. Europa del año mil a la colonización de América, pról. de J. Le Goff, trad. de A. Vázquez Barrón y M. Sánchez Ventura, México: Fondo de Cultura Económica, Embajada de Francia en México, 2009.

Berceo, Gonzalo de, Milagros de Nuestra Señora, ed., estudio y notas de Fernando Baños Vallejo, Madrid: Real Academia Española, 2011.

Carmona Muela, Juan, Iconografía cristiana. Guía básica para estudiantes, Madrid: Akal, 1998.

Delmar, Fernando, El ojo espiritual. Imagen y naturaleza en la Edad Media, México: Universidad Nacional Autónoma de México, 1993.

Harpus, PATrick, La tradición oculta del alma, trad. de I. Margelí, Girona: Atalanta, 2013. INGARDEN, ROMAN, “Concretización y reconstrucción”, en D. Rall (comp.), En busca del texto. Teoría de la recepción literaria, México: Universidad Nacional Autónoma de México, 2008, 31-54.

Medievalia 49, 2017, pp. 101-120 
Isidoro de Sevilla, SAN, Etimologías, ed. de J. Oroz Reta y M. A. Marcos Casquero, intr. de M. C. Díaz y Díaz, Madrid: Biblioteca de Autores Cristianos, 2004.

Limoges de, Pedro, Libro devoto y útil del ojo espiritual por semejanza con el ojo material, intr. de E. Graue Wiechers, trad. de M. Martínez Peñaloza, México: Fundación de Asistencia Privada Conde de Valenciana, 2012.

Herrero Romero, Lucrecia, "Notas iconográficas sobre el tránsito del alma en el románico español”, en J. Yarza Luaces (ed.), Estudios de iconografía medieval española, Bellaterra: Universidad Autónoma de Barcelona, 1984, 13-51.

Real Academia Española, Diccionario de la lengua española, 2001 (consultado en www.rae.es).

Ruiz Domínguez, Juan Antonio, El mundo espiritual de Gonzalo de Berceo, Logroño: Gobierno de La Rioja-Instituto de Estudios Riojanos, 1999.

Soto-Hay García, Fernando, Signos y símbolos sagrados I: guía de estudios para los cursos para la licenciatura en ciencias de la religión, México: Universidad Iberoamericana, 1995.

\section{BIBLIOGRAFÍA DE CONSULTA}

Berceo, Gonzalo de, El libro de los Milagros de Nuestra Señora, ed. y estudio de Jesús Montoya Martínez, Granada: Universidad de Granada, 1986.

Berceo, Gonzalo de, Milagros de Nuestra Señora, ed. de Juan Manuel Rozas López, Barcelona: Plaza y Janés, 1986.

Berceo, Gonzalo de, Milagros de Nuestra Señora, ed. de Juan Carlos Bayo e Ian Michael, Madrid: Castalia, 2006.

Berceo, Gonzalo de, Obras completas II. Los Milagros de Nuestra Señora, estudio y ed. de Brian Dutton, London: Tamesis, 1971.

LE Goff, JACQUes, Lo maravilloso y lo cotidiano en el Occidente medieval, Barcelona: Gedisa, 2008.

Le Goff, Jacques y Nicolas Truong, Una historia del cuerpo en la Edad Media, Barcelona: Paidós, 2005.

Olivares Zorrilla, Rocío, La imagen luminosa en dos obras de Gonzalo de Berceo, México: Sindicato de Trabajadores Académicos de la Universidad Autónoma Chapingo, 1991.

Patch, Howard Rollin, El otro mundo en la literatura medieval, México: Fondo de Cultura Económica, 1956.

Rubial, Antonio, "Entre el cielo y el infierno. Cuerpo, religión y herejía en la Edad Media tardía”, Acta Poética. Cultura y Literatura Medievales, 20, 1999, 19-46. 